\title{
$<$ ERRATUM $>$ Four Cases of Grooming Sessions between Chimpanzees and Guenons at the Kalinzu Forest Reserve, Uganda
}

\section{$\operatorname{AUTHOR}(\mathrm{S}):$}

Tsutaya, Takumi; Aruga, Natsumi; Matsuo, Hodaka; Hashimoto, Chie

\section{CITATION:}

Tsutaya, Takumi ...[et al]. <ERRATUM>Four Cases of Grooming Sessions between

Chimpanzees and Guenons at the Kalinzu Forest Reserve, Uganda. Pan Africa News 2018, 25(2): $29-29$

ISSUE DATE:

2018-12

URL:

http://hdl.handle.net/2433/236294

RIGHT:

Copyright (C) Pan Africa News. 


\title{
Four Cases of Grooming Sessions between Chimpanzees and Guenons at the Kalinzu Forest Reserve, Uganda
}

\author{
Takumi Tsutaya, Natsumi Aruga, Hodaka Matsuo, \& Chie Hashimoto
}

Pan Africa News 25(1), 5-7 (2018)

Owing to a technical error, a number indicating affiliation and address of some authors was typed incorrectly as "2 2 Primate Research Institute, Kyoto University, Aichi, Japan" instead of " $\underline{3}$ Primate Research Institute, Kyoto University, Aichi, Japan" in the print and the KURENAI versions. This error has been corrected in the HTML version at http://mahale.main.jp/PAN/2018/003.html. 